\title{
FORMAÇÃO ACADÊMICA EM SAÚDE FAMILIAR: RELATO DE UMA EXPERIÊNCIA MULTIPROFISSIONAL
}

\author{
Stella Maris Hildebrand \\ Oviromar Flores ${ }^{2}$ \\ Milton Menezes da Costa Neto
}

\section{INTRODUÇÃO}

O Movimento da Reforma Sanitária e o processo de construção do Sistema Único de Saúde (SUS) marcam momentos significativos do processo de resgate da cidadania dos brasileiros no campo da saúde. Foi ao longo das últimas quatro décadas que se plantou a idéia da equidade, integralidade, universalidade e intersetorialidade como princípios orientadores das nossas práticas assistenciais em saúde.

Em termos jurídicos, as reorientações no setor saúde tornam-se particularmente importantes após a promulgação da constituição de 1988 e da Lei Orgânica da Saúde (Lei 8.080), de 19 de setembro de 1990, complementada pela Lei 8.142, de 28 de dezembro de 1999, a qual trata da participa-

Enquanto os serviços de saúde têm como competência o treinamento dos profissionais, cabe às universidades 0 ensino de graduação e pós-graduação bem como o assessoramento e a participação no planejamento e implementação das práticas assistenciais, recomendando-se que estas instituições envolvam-se no desenvolvimento da força de trabalho em saúde com ações articuladas e de co-participação.

ção e do controle social, embora saibamos que a letra fria da lei, ainda que seja esta uma das mais completas em termos mundiais, não é suficiente para a garantia do direito à saúde dos brasileiros de forma universal, integral e equânime, uma vez que este estará sempre relacionado ao poder acumulado e à capacidade demonstrada pelos distintos grupos sociais que compõem a nossa sociedade, visando a sua garantia e ao seu exercício (do direito à saúde).

Em termos práticos, ao longo de quarenta anos a sociedade brasileira tem vivenciado a contraposição de propostas ao modelo biomédico dominante, seja em termos de extensão de cobertura, saúde comunitária, saúde familiar, promoção à saúde, modelos estes articulados por agências internacionais, a partir de resultados positivos apresentados por outros países.

É importante que se reconheça, no entanto, que no Brasil, assim como em outros países, esses modelos assumem sempre as marcas dos contextos sócio-político-sanitários vigentes no processo da sua construção, adquirindo, como não poderia deixar de ser, características que nos são peculiares. Além disso, nessa seqüência, é possível constatar que as diferenças que marcam esses modelos não decorrem apenas da "acumulação de conhecimentos" ao longo do tempo. Eles diferem em termos de abrangência, de qualidade, de tecnologia e de noção de direito em saúde, o que nos sugere alguns avanços em termos de aproximação dos princípios acima referidos. Por exemplo, enquanto nas práticas assistenciais características do modelo da Saúde Comunitária, segundo alguns autores, o que se propunha era uma medicina simples, para pessoas simples com problemas

${ }^{1}$ Enfermeira. Professora Assistente IV do Departamento de Enfermagem/UnB. Mestre em Enfermagem Fundamental.

2 Sociólogo. Professor Assistente I. do Departamento de Saúde Coletiva/UnB. Mestre em Saúde Comunitária

${ }^{3}$ Médico. Departamento de Atenção Básica. Secretaria de Assistência à Saúde do Ministério da Saúde. Mestre em Educação 
simples, na estratégia da Saúde Familiar, o que se defende é uma atenção à saúde com qualidade e efetividade; que tem como foco a família no seu espaço domicílio como locus de intervenção e que, na perspectiva do ideário da Promoção da Saúde, supõe como condição fundamental o poder e a capacidade desses grupos sociais no sentido da articulação, construção e defesa dos seus direitos em saúde.

Transparece aqui uma clara inflexão no sentido político-pedagógico das práticas assistenciais, já que o seu componente educativo é proposto como a mediação da participação popular em saúde, entendida aqui como o processo em que os grupos sociais estarão articulados de maneira autônoma e criativa face às autoridades da saúde.

O Programa de Saúde Familiar (PSF) foi criado pelo Ministério da Saúde em 1994, como uma das formas de enfrentamento dos limites do modelo assistencial dominante centrado na doença e no hospital, passando a priorizar as ações de proteção e promoção à saúde dos indivíduos e da família, tanto adultos, quanto crianças, sadias ou doentes, de forma integral e contínua (BRASIL, 1994).

Um dos desafios na implantação do PSF é a formação e capacitação de profissionais de saúde, sendo criado com essa finalidade os Pólos de Capacitação em Saúde da Família (PCSF), vinculando a universidade e os serviços no processo de reordenação das práticas de saúde de atenção à saúde, que tem como suposto a disponibilidade de uma força de trabalho que apresente novas habilidades técnicas, cognitivas e valores comprometidos com o bem estar social e as transformações necessárias nesse sentido. Estes fatos colocam questões à universidade e à rede de serviços que dizem respeito à urgência das reordenações no espaço acadêmico assim como no espaço assistencial, chamando a atenção para problemas que dizem respeito às questões relacionadoas ao tempo técnico/tempo político de ambas instituições.

Enquanto os serviços de saúde têm como competência o treinamento dos profissionais, cabe às universidades o ensino de graduação e pós-graduação bem como o assessoramento e a participação no planejamento e implementação das práticas assistenciais, recomendando-se que estas instituições envolvam-se no desenvolvimento da força de trabalho em saúde com ações articuladas e de co-participação.

Do lado da universidade o tempo técnico e o tempo político apontam para a sua capacidade de absorção da saúde familiar como uma estratégia assistencial, da sua crença nela e da sua aceitação e defesa por parte do seu quadro docente. Principalmente, por parte de algumas categorias profissionais, e acima de tudo, da sua capacidade de contemplar esta estratégia nas propostas curriculares dos seus Cursos. Isto é, estes tempos falam do comprometimento, da atualização e da efetividade das respostas da Universidade Brasileira em relação às necessidades mais prementes da sociedade.

Do lado da rede de serviços, estes mesmos tempos, falam-nos da capacidadade da rede de serviços colocar-se diante do novo, que se traduz numa reorientação radical em termos de conhecimentos, tecnologias e estruturação das suas práticas, que apontem para a interdisciplinaridade e intersetorialidade na perspectiva de uma nova rede de serviços; mais ágil e mais efetiva, mediada por uma maior aproximação entre profissional e grupos sociais usuários dela.

Nesta dialética, em que interagem universidade/rede de serviços/grupos sociais usuários, os espaços institucionais demarcados pela academia e pelas práticas assistenciais revelam-se lugares de exercício de poder, de articulação de distintos e conflituosos interesses, exercendo determinações fundamentais tanto na restruturação dos serviços como na reorientação das propostas pedagógicas necessárias nessa direção.

Este estudo pretende relatar a experiência da disciplina de Saúde Familiar, oferecida em nível de graduação, pelo Departamento de Saúde Coletiva (DSC) da Faculdade de Ciências da Saúde (FS) da Universidade de Brasília (UnB). Desta Disciplina participaram alunos dos diversos Cursos da FS, além de alunos do Curso de Serviço Social, sendo ministrada por três professores, quando se objetivou exercitar a interdisciplinariedade como elemento contribuinte no processo de construção do conhecimento na área de saúde familiar, de modo articulado com a rede de serviços da Secretaria de Saúde. 
Formação Acadêmica em Saúde Familiar...

\section{A EXPERIÊNCIA ACADÊMICA MULTIPROFISSIONAL EM SAÚDE DA FAMÍLIA: MATERIAL E MÉ- TODO}

A Faculdade de Ciências da Saúde (FS) da Universidade de Brasília (UnB), através do Departamento de Saúde Coletiva (DSC) oferece a disciplina Saúde Familiar, com carga horária de 60 horas, equivalente a quatro (04) créditos, na modalidade "disciplina optativa", há quase uma década.

De início, esta Disciplina foi desenvolvida de forma teórica, concentrando-se em aspectos predominantemente psicossociais da família, sendo oferecida a alunos da Medicina, Enfermagem, Odontologia e Nutrição.

Este enfoque persistiu até 1994, quando iniciou-se a análise de experiências internacionais e nacionais e foram introduzidos conteúdos que apontavam para a construção da saúde familiar como estratégia de reordenação da atenção à saúde. Com a implantação do PSF no Distrito Federal, em 1996 os conteúdos e metodologias foram direcionados para atender os pressupostos deste Programa. A partir de então, um ou mais professores do DSC eram responsáveis pela disciplina, não tendo ocorrido até então qualquer tentativa de articulação com outros cursos da FS ou da UnB com vistas à discussão da saúde familiar.

A iniciativa de reorientação desta disciplina partiu de professores do Departamento de Saúde Coletiva, no início do segundo semestre de 1999, que promoveram reuniões com docentes dos Cursos da FS, buscando a elaboração de uma proposta que colocasse em termos acadêmicos a questão da interdisciplinaridade da saúde familiar mediante a participação de professores com distintas formações e habilitações, oriundos de deferentes Cursos ou Departamentos; a participação de alunos originários dos Cursos da FS e da Faculdade de Serviços Social; a incorporação dos componentes graduados da equipe de saúde familiar na experiência a ser iniciada.

A equipe responsável pela re-elaboração da disciplina foi composta pelos professores: João de Abreu Branco Júnior (médico - Fundação Hospitalar do Distrito Federal), Pedro Luiz Tauil (MédicoDepartamento de Saúde Coletiva) Milton Menezes da Costa Neto (médico - Departamento de Atenção Básica/MS), Oviromar Flores (sociólogo - Departamento de Saúde Coletiva/FS/UnB), Paulo Sérgio França (médico - Departamento de Ginecologia, Obstetrícia e Pediatria/ FS/UnB) e Stella Maris Hildebrand (enfermeira - Departamento de Enfermagem/FS/UnB).

Esta equipe reuniu-se várias vezes discutindo, também, o distanciamento da Faculdade de Saúde, no que diz respeito a outras iniciativas que capacitassem os alunos para as práticas de saúde familiar; constatando-se uma expressiva resistência do corpo docente no sentido de compreensão, incorporação e defesa da nova estratégia, o que passava para os alunos, principalmente para os alunos do Curso de Medicina.

Aliado a esse fato - do lado da Secretaria de Saúde - no início do ano de 1999, as práticas de saúde familiar até então denominadas "Programa de Saúde em Casa", com a mudança de governo no DF, sofrem uma interrupção com suspensão das atividades e demissão dos profissionais, sobe a alegação de necessidade de ajustes de cunho técnico e administrativo. Este fato reforçou entre os alunos a descrença e a resistência a respeito da Saúde da Família, manifestos de modo muito articulado com um total desconhecimento sobre o assunto.

Saliente-se que nesse quadro, os Cursos de Enfermagem e de Odontologia já desenvolviam atividades de campo relacionadas com as práticas de Saúde da Família, e que até então, o maior número de alunos participantes da Disciplina era proveniente do Curso de Enfermagem, os quais mostravam-se mais sensibilizados com os assuntos e questões levantadas em sala de aula.

Os alunos do Curso de Medicina, talvez pelo fato de o ensino ser centrado no hospital, participavam em número muito exíguo, e freqüentemente reagiam aos conteúdos da disciplina como conhecimentos de segunda categoria, que diziam respeito a um modelo que vinha para destruir a prática médica. É importante considerar que nos anos de 1998 e 1999, a Faculdade de Ciências da Saúde/ UnB foi marcada por uma acirrada discussão que culminou com a criação da "Faculdade de Medicina", em dezembro de 1999, juntamente com a discussão da possível criação de outras faculdades como (odontologia, enfermagem, nutrição e farmácia). Em relação à Faculdade de Medicina, as razões para a sua criação centravam-se no exíguo poder dos médicos face aos outros profissionais no 
âmbito da Faculdade de Ciências da Saúde. A proposta do grupo de médicos docentes, encaminhada ao Conselho Universitário, defendia o Hospital Universitário como "o lugar do ensino médico", aliada à defesa da excelência da capacitação como unicamente relacionada a tecnologias sofisticadas, o que implicava uma certa negação da multiprofissionalidade e interdisciplinariedade no ensino. Além disso, a referida proposta aprovada não continha o desenho do modelo pedagógico a ser adotado pela nova Faculdade.

Face este quadro, avaliou-se a necessidade de promover a divulgação e esclarecimento sobre a Disciplina e sobre a Saúde Familiar, através de um folheto informativo divulgado na FS e UnB antes e durante o período de matrícula dos alunos da graduação. Concomitantemente a isto, os professores participantes do grupo de discussão foram solicitados a discutirem a nova proposta da Disciplina com os alunos no final do primeiro semestre de 1999.

Dessa forma, para o segundo semestre de 1999 foram ofertadas 30 vagas para os alunos dos cursos de medicina, enfermagem, nutrição, odontologia, farmácia e serviço social. A população que participou do estudo constituiu-se de alunos dos seguintes cursos: dois (02) medicina, do sexto e oitavo semestre; um (01) odontologia do quarto semestre, sete (07) enfermagem do quarto ao sétimo semestre, sete (07) serviço social do sexto ao oitavo semestre; três (03) docentes (autores deste trabalho), a equipe do PSF da unidade e as famílias visitadas na atividade prática. Dentre os alunos participantes, havia um monitor que auxiliava os docentes nas atividades desenvolvidas.

O objetivo da disciplina foi proporcionar aos alunos a oportunidade de analisar o modelo de atenção da saúde familiar, sendo capazes de compreender os diversos fatores que alteram o equilíbrio entre o indivíduo e o ambiente, de visualizarem a saúde em seu sentido mais amplo, estando aptos a perceber a atuação profissional sob os enfoques de integralidade, eqüidade, universalidade, intersetorialidade, no sentido de promover, manter e restabelecer a saúde da família e seus componentes, realizando um trabalho multiprofissional e interdisciplinar com a participação da população.

O desenvolvimento da referida disciplina transcorreu em dois momentos que se integraram de forma permanente: o teórico-conceitual e o prático. Ambos foram desenvolvidos de forma articulada, intercalando períodos de concentração e de dispersão, os quais se deram no cotidiano de uma Unidade de Saúde da Família da Fundação da Hospitalar de Saúde do Distrito Federal (FHDF).

Para uma melhor visualização do desenvolvimento da Disciplina, neste semestre, é importante que se chame a atenção para o fato de que a trajetória do PSF na Secretaria de Saúde do Distrito Federal iniciou em 1995 com a implantação do SUS, aprovada na II Conferência Distrital de Saúde. Em 1996, a IV Conferência Distrital de Saúde aprova o novo modelo de atenção à saúde denominado "REMA" (DISTRITO FEDERAL, 1996) contendo uma agenda técnica e política explicitando as ações para a reformulação do modelo assistencial. O Conselho de Saúde do DF aprova a implantação do PSF denominado de "Saúde em Casa" - em dezembro de 1996 e em janeiro de 1997 é celebrado convênio com o Instituto Candango de Solidariedade para a contratação de pessoal até 1999.

No início de 1999 o novo Governador eleito extinguiu o "Saúde em Casa", demitindo o seu quadro de pessoal e criando o Programa de Saúde da Família. A proposta de Planejamento e Orçamento Participativo desenvolvida até então não foi mantida e as informações sobre a situação de saúde disponíveis até aquela data não foram levadas em consideração, demandando o reinicio do cadastramento das famílias: recomposição e o treinamento de novas equipes.

Conseqüentemente os alunos desenvolveram suas atividades práticas numa Unidade de Saúde em fase de execução das ações previstas no planejamento local após terem realizado as etapas de cadastramento e diagnóstico, a qual possuía uma equipe de saúde da família completa (agente de saúde, auxiliar de enfermagem, assistente social, médico, enfermeiro, odontólogo, técnico em higiene bucal e auxiliar odontológico).

O território de intervenção foi dividido em cinco micro-áreas homogêneas com 1.200 famílias, totalizando aproximadamente 4.000 pessoas. O recadastramento da população foi realizado em $45-$ 50 dias, apresentou 61 recusas ("por motivos políticos" - segundo verbalização da coordenadora da equipe).

O planejamento local foi realizado a partir de uma reunião com o Conselho de Saúde Local, no qual foram priorizados os seguintes problemas: hipertensão arterial, diabetes, acompanhamento da 
gestação, acompanhamento da criança, tabagismo e alcoolismo. O uso de drogas ilícitas também foi identificado como um problema de saúde de alta incidência.

Enquanto na disciplina, os conteúdos enfocaram aspectos da abordagem coletiva, familiar e individual, a saber:

a) aspectos da abordagem coletiva: a estratégia da saúde familiar no contexto do SUS; os serviços de saúde e sua relação com a continuidade das ações; o uso da epidemiologia e do planejamento como instrumentos de trabalho; ações interdisciplinares e multisetoriais; dinâmica do funcionamento da unidade do PSF;

b) aspectos da abordagem familiar: organização e dinâmica familiar; características/tipologia; sub-sistemas sociais; crise na dinâmica familiar; visão sistêmica da família;

c) aspectos da abordagem individual: articulação das práticas preventivas - curativas reabilitadoras; complementaridade do modelo clínico e modelo epidemiológico social; o ciclo de vida do indivíduo no contexto familiar e social seus problemas clínicos e determinantes sociais.

Na primeira atividade de campo, os alunos acompanharam a equipe local nas visitas domiciliares agendadas (dois alunos com um profissional da equipe), as quais eram objeto de uma breve exposição do profissional da equipe que as realizariam, relatando cada situação a ser encontrada nos domicílios e o motivo da visita. Neste momento, os alunos realizaram a prática de observação livre, sem roteiro pré-estabelecido. Este primeiro trabalho de campo foi precedido de uma reunião do grupo de alunos com a Coordenadora da Unidade de Saúde, quando foram discutidos temas do conteúdo que deram suporte à compreensão da atividade e a trajetória percorrida pelos profissionais.

No retorno dos alunos à situação de aula em momentos teórico-conceituais, após as experiências práticas, era realizado o relato e a análise da experiência, articulado com reflexão sobre o modelo de assistência em pauta, quando eram levantadas questões relativas as intervenções realizadas, segundo sua natureza (promoção, prevenção, tratamento, encaminhamento e outras); o relacionamento profissional - família, a comunicação interpessoal e o contexto social de inserção da família. Com base nas discussões realizadas, e na permanência de questões teóricas não esgotadas suficientemente eram sugeridas bibliografias para discussão na aula posterior.

Ao mesmo tempo, destas discussões extraíam-se temas a serem explorados no sentido de ampliar a compreensão da prática, as quais passavam a incorporar um roteiro semi - estruturado contendo questões a cerca do gerenciamento, dinâmica organizacional do serviço e atividade de visita domiciliar. As questões do referido roteiro eram levantadas com a equipe da Unidade e com as famílias em situação de visita domiciliar. Posteriormente, os dados colhidos eram confrontados com às bases teóricas desenvolvidas, incentivando-se a crítica e a criatividade dos alunos rumo a sugestões para superação dos obstáculos/ fatores limitantes existentes na assistência local. Vale ressaltar, que os alunos participaram de visitas domiciliares a várias famílias acompanhados de diferentes componentes da equipe, oportunizando a vivência de diferentes atuações profissionais.

Foi incorporada como atividade da Disciplina a "Primeira Amostra Nacional de Produção em Saúde da Família" realizada em Brasília, no período de 22 a 25 de novembro, quando os alunos foram solicitados a selecionarem uma das experiências relatadas para análise e posterior relato em situação de sala de aula.

O sistema de avaliação constou de: relatórios das visitas; relatório referente à experiência selecionada na "Primeira Amostra Nacional de Produção em Saúde da Família"; uma prova escrita individual onde os alunos discorreram sobre os nós críticos identificados na experiência observada ao longo do semestre; e, avaliação da participação individual em termọs de freqüência, pontualidade, qualidade das intervenções.

A disciplina foi avaliada em todos os encontros onde os alunos identificaram dificuldades e facilidades, sugerindo mudanças. Ao final do semestre foi avaliado o processo de construção do conhecimento sob a ótica dos objetivos propostos pela disciplina, material e método utilizados.

\section{RESULTADOS}

É importante considerar que no semestre anterior à realização desta experiência (primeiro 
semestre de 1999) a turma de alunos da Disciplina era composta por três alunos (um da odontologia, um da medicina e um da enfermagem), sendo que no segundo semestre o número de participantes foi de vinte alunos, havendo uma desistência (um aluno da medicina), por motivos de saúde.

As atividades foram desenvolvidas às terças-feiras, no horário das 1.4 às 18:00 horas, apresentando um índice médio de $95 \%$ de presença, tanto em sala de aula como no trahalho de campo. Nas atividades extra-classe os alunos utilizavam transporte próprio ou carona, apresentando um grau satisfatório de pontualidade, uma vez que a saída da equipe para a visita domiciliar ficava condicionada a presença dos mesmos.

Ficou patente o interesse dos alunos nas discussões em sala de aula, sendo que o dado mais valorizado nos seus depoimentos era o contato com o cotidiano das famílias, do qual eles extraíam conclusões importantes do tipo:

... O trabalhador da saúde precisa entender que no seu contato com o usuário ele precisa aprender a ouvir. Muitas vezes nossos clientes querem falar das suas dores da vida, a sua viuvez, a sua falta de emprego, a droga do filho, a gravidez da filha adolescente, e nós não Ihe damos ouvidos e ficamos insistindo na questão da doença. Frustrados. O familiar fica frustrado, pois se estabelece um diálogo entre surdos (aluno de enfermagem).

... das Disciplinas do Departamento de Saúde Coletiva que eu fiz, esta é a melhor, pois me deu a noção do que me espera aí fora. (aluno da medicina)

... com esta experiência, nós do serviço social, pudemos compreender a ótica dos profissionais de saúde que vão trabalhar conosco no futuro, situação que não vivemos durante a formação acadêmica. (aluno do serviço social)

Ao mesmo tempo, os alunos conseguiam contrapor os limites das práticas observadas como relacionados à insipiência da experiência e da equipe, à sua interrupção, à falta de mecanismos de participação e controle por parte da população e a conseqüente falta de legitimação do Programa face a essa mesma população.

No que se refere à diversidade de cursos do grupo participante, este dado foi particularmente importante, na medida em que a emoção e a força da experiência numa localidade periférica do Distrito Federal, em situação de marginalização, fez emergir múltiplas variáveis a partir das suas concepções de mundo, permitindo o confronto e a troca de valores e atitudes nos momentos de discussão oportunizados pela disciplina.

Estes fatos sugerem que a multiprofissionalidade e interdisciplinaridade são componentes fundamentais para a formação dos trabalhadores de saúde e para a efetiva implantação do PSF, como proposta de transformação do paradigma sanitário e das práticas de saúde. Vivenciar este cotidiano durante a formação acadêmica aproxima e mescla os "saberes e fazeres" específicos, em busca de um objetivo comum, possibilitando a ampliação do conhecimento e a visão sobre o outro profissional.

Os alunos puderam analisar o modelo de atenção de saúde familiar tanto em sua concepção teórica, como também na prática local e comparar com experiências nacionais. Verificaram as dificuldades da equipe de saúde da família em executar práticas de saúde com integralidade entre os componentes e os demais níveis de assistência. As ações de prevenção e promoção muitas vezes, eram preteridas em função da urgência de intervenções para o restabelecimento da saúde.

A assistência domiciliar, foi percebida pelos alunos como uma ferramenta que toca em questões de cunho ético, cognitivo; do contexto social e da infra-estrutura da família, exigindo uma permanente reflexão sobre as interfaces do universo familiar com o sucesso da ação dos profissionais de saúde.

Estas considerações valem, também, para o grupo de professores e para a equipe profissional da unidade de saúde observada. Com relação aos professores, este grupo esteve presente na maioria das aulas, revelando-se importante não só a presença como a complementaridade das experiências e conhecimento dos seus componentes, contando sempre com o suporte da equipe de profissionais que subsidiavam-nos com dados de realidade, o que, por certo implicou em maior concretude para o processo de aprendizado do grupo. 


\section{CONSIDERAÇÕES FINAIS}

Temos, então, que o Programa de Saúde Familiar enquanto estratégia de construção do SUS requer uma concepção positiva do processo saúde-doença; orientado por um paradigma sanitário de produção social da saúde que aponte para cidades saudáveis mediante a formulação de políticas públicas saudáveis, o que demanda tempos distintos, uma vez que as mudanças decorrentes são de ordem política, ideológica e cognitivo-tecnológica. Segundo Mendes (I996, p.234):

"A mudança será política porque envolve distintos atores sociais em situação, portadores de diferentes projetos devendo, para hegemonizar-se, acumular capital político. Tem, também, uma dimensão ideológica, uma vez que ao se estruturar na lógica da atenção às necessidades de saúde da população, implicitamente opta por nova concepção de processo saúdedoença e por novo paradigma sanitário, cuja implantação tem nítido caráter de mudança cultural. Por fim, apresenta uma dimensão cognitiva-tecnológica que exige a produção e utilização de conhecimentos e técnicas coerentes com os supostos políticos e ideológicos do projeto da produção social da saúde"

Um processo dessa natureza, impõe aos seus atores, uma atuação inter e multidisciplinar para atender o princípio de integralidade do atendimento à população/famílias que residem na área de abrangência do programa, a exemplo do Projeto UNI no Brasil e América Latina (Almeida; Feuererker; Llanos, 1999) que visava as transformações no ensino e na prática da saúde, estabelecendo uma nova relação entre usuários/comunidades, formadores e prestadores de serviços de saúde.

Resultados positivos nesse Projeto operaram-se mediante a discussão e negociação profunda do seu ideário e a implantação de experiências concretas, apontando para a possibilidade de mudanças institucionais sustentáveis que atualmente permanecem como tais ou inspiram experiências de saúde familiar.

O princípio de universalidade da assistência no PSF, ainda não pode ser detectado para toda a população brasileira no que tange ao acesso e a cobertura destes serviços. Atualmente existem 4.945 equipes de saúde familiar, distribuídas em 1.870 municípios brasileiros, o que corresponde a uma cobertura populacional equivalente a 17.060 .250 habitantes (BRASIL, 2000, p. 11).

Este novo modelo de atenção está sendo implantado com diferentes velocidades, dimensões e abrangências nos municípios. Segundo o Ministro da Saúde José Serra, em seu pronunciamento no I Seminário de Experiências Internacionais em Saúde da Família expressou as metas do PSF:

\footnotetext{
"Anunciamos as metas de elevar para 3.500 o número de equipes até o final deste ano, para 7 mil no final de 1999 e para 10 mil no ano 2000. Para cobrir a população inteira do país, precisamos de umas 40 mil equipes. Com o subsídio federal, isto custa pouco mais de $R \$ 1$ bilhão, somando-se estados e municípios. O Governo Federal tem metade da receita tributária disponível e gasta duas vezes mais que os estados e municípios, ou seja: se a receita tributária disponível após a transferência for de 100, o Governo Federal tem 50 e estados e municípios outros 50, mas o Governo gasta 2/3 mais enquanto estados e municípios gastam 1/3. Apoiamos uma proposta de emenda constitucional que corrigirá isso, aumentando um pouco os compromissos orçamentários com a Saúde para o nível federal e também para estados e municípios, em um". processo que terá que ser necessariamente gradual. Acreditamos que parte desse aumento do investimento de estados e municípios deve acontecer nos Programas de Saúde da Família" (BRASIL, 1999a, p. 16).
}

Com relação ao crescimento do PSF, em 1999, observou-se que, Rondônia foi o estado que mais cresceu em número de municípios com PSF (75\%) e Roraima com o número de equipes implantadas; o Distrito Federal apresentou a menor taxa de crescimento de equipes de PSF (-62.9\%) e Bahia com a menor taxa de crescimento de municípios com PSF (2.7\%), (BRASIL, 2000, p. 11).

Diante deste este processo de mudança, um dos maiores desafios a ser enfrentado é a formação e educação continuada dos profissionais para a realização do processo de trabalho pautado nas bases conceituais da nova prática esperada. Neste sentido, esforços nacionais estão sendo concen- 
trados para promover um processo educativo congruente com as bases conceituais-práticas do PSF.

Dentre as atividades educativas vislumbram-se experiências que estão sendo desenvolvidas pelas Instituições de Ensino Médio e Superior, assim como pelas Secretarias de Saúde dos estados e municípios, buscando estabelecer relações de intersetorialidade e multiprofissionalidade, em parceria, para promover a convergência das premissas e paradigmas solidificando as transformações pretendidas em direção única, mas que também seja flexível e permeável à dinâmica social em curso.

A experiência do Projeto UNI (Almeida; Feuererker; Llanos, 1999), mesmo naqueles projetos onde as mudanças não se efetivaram, foi capaz de produzir reflexões sobre os limites e dificuldades face a transformações em contextos desfavoráveis, nos ensinou sobre a importância da vivência cotidiana das contradições e a compreensão dos elementos de cunho políticos, históricos, sociais que reduzem a adesão, seja ela acadêmica, dos grupos sociais ou dos trabalhadores da saúde em projeto como o PSF.

Do lado dos nossos alunos, aprendemos a vivenciar as suas decepções e temores a respeito da nova estratégia da saúde familiar no início da Disciplina, sentimentos estes que gradativamente deram lugar a um otimismo com base na sua melhor compreensão e no desenvolvimento da capacidade de observar, refletir, agir ou propor soluções.

Do lado da equipe da Unidade de Saúde, aprendemos que na situação analisada, não Ihes punha medo a questão "por onde começamos", pois PSF está no início e isto é um processo. Parecenos que a questão central que se coloca para a equipe é a construção da sua direção, para onde caminhar, de modo aliado com a população.

Da mesma forma, outras experiências mais avançadas em Saúde da Família, com pólos de capacitação mais estruturados, fornecem-nos sinais da possibilidade de avanços de um projeto pedagógico articulado às práticas de saúde, sem contudo dar-nos as soluções, mas mostrando caminhos possíveis diante da estrutura das nossas práticas de saúde.

Com relação à Disciplina de Saúde Familiar, considerou-se que da forma como foi estruturada, ela está apropriada para estudantes a partir do quarto ou quinto semestre. No entanto, avaliou-se, a possibilidade de que ela fosse recriada na versão I e II. Saúde Familiar I , de cunho obrigatório, seria destinada aos alunos do primeiro semestre, inclusive aqueles oriundos da Psicologia e Serviço Social; e Saúde Familiar II seria oferecida como Disciplina optativa a alunos interessados em um nível de intervenção mais direto e complexo.

\section{REFERÊNCIAS BIBLIOGRAFICAS}

ALMEIDA, M.; FEUERERKER, L.; LLANOS, M. Educação dos profissionais de saúde na América Latina: teoria e prática de um movimento de mudança. São Paulo: Hucitec; Buenos Aires: Lugar Editorial; Londrina: Ed. UEL, 1999. 2 v.

BRASIL. Ministério da Saúde. Fundação Nacional de Saúde. Saúde dentro de casa: programa de saúde da família. Brasília, 1994.

BRASIL. Ministério da Saúde. Secretaria de Assistência à Saúde/Coordenação de Saúde da Comunidade. SEMINÁRIO EXPERIENCIAS INTERNACIONAIS EM SAÚDE DA FAMÍLIA, 1., 1999, Brasília. Relatório Final. p. 16.

BRASIL. Ministério da Saúde. Departamento de Atenção Básica. Programas e projetos. (on line). Disponível Internet via www.URL:http://www.saúde.gov.br/programas/pacs/psf.htm. Arquivo capturado em 27 de janeiro de 2000.

DISTRITO FEDERAL. Secretaria de Saúde. Reformulação do modelo atenção à saúde no Distrito Federal. Revista de Saúde do Distrito Federal, Brasília, v. 2,n. 2, p.5-9, abr./jun. 1996.

MENDES, E. V. Uma agenda para a saúde. São Paulo: Hucitec, 1996. 